\title{
Mast cell activation and arterial hypotension during proximal aortic repair requiring hypothermic circulatory arrest
}

\author{
Miklos D. Kertai, MD, PhD, ${ }^{a}$ Sreekanth Cheruku, MD, ${ }^{a}$ Wenjing Qi, PhD, ${ }^{b}$ Yi-Ju Li, PhD, \\ G. Chad Hughes, MD, ${ }^{d}$ Joseph P. Mathew, MD, MHSc, ${ }^{a}$ and Jörn A. Karhausen, MD ${ }^{a}$
}

\section{ABSTRACT}

Objective: Aortic surgeries requiring hypothermic circulatory arrest evoke systemic inflammatory responses that often manifest as vasoplegia and hypotension. Because mast cells can rapidly release vasoactive and proinflammatory effectors, we investigated their role in intraoperative hypotension.

Methods: We studied 31 patients undergoing proximal aortic repair with hypothermic circulatory arrest between June 2013 and April 2015 at Duke University Medical Center. Plasma samples were obtained at different intraoperative time points to quantify chymase, interleukin-6, interleukin-8, tumor necrosis factor alpha, and white blood cell CD11b expression. Hypotension was defined as the area (minutes $\times$ millimeters mercury) below a mean arterial pressure of $55 \mathrm{~mm}$ $\mathrm{Hg}$. Biomarker responses and their association with intraoperative hypotension were analyzed by 2 -sample $t$ test and Wilcoxon rank sum test. Multivariable logistic regression analysis was used to examine the association between clinical variables and elevated chymase levels.

Results: Mast cell-specific chymase increased from a median $0.97 \mathrm{pg} / \mathrm{mg}$ (interquartile range $[\mathrm{IQR}], 0.01-1.84 \mathrm{pg} / \mathrm{mg}$ ) plasma protein at baseline to $5.74 \mathrm{pg} / \mathrm{mg}$ (IQR, 2.91-9.48 pg/mg) plasma protein after instituting cardiopulmonary bypass, $6.16 \mathrm{pg} / \mathrm{mg}$ (IQR, 3.60-9.41 pg/mg) plasma protein after completing circulatory arrest, and $7.64 \mathrm{pg} / \mathrm{mg}$ (IQR, 4.63-12.71 pg/mg) plasma protein after weaning from cardiopulmonary bypass (each $P$ value $<.0001$ vs baseline). Chymase was the only biomarker associated with hypotension during $(P=.0255)$ and after $(P=.0221)$ cardiopulmonary bypass. Increased temperatures at circulatory arrest and low presurgical hemoglobin levels were independent predictors of increased chymase responses.

Conclusions: Mast cell activation occurs in cardiac surgery requiring cardiopulmonary bypass and hypothermic circulatory arrest and is associated with intraoperative hypotension. (J Thorac Cardiovasc Surg 2017;153:68-76)

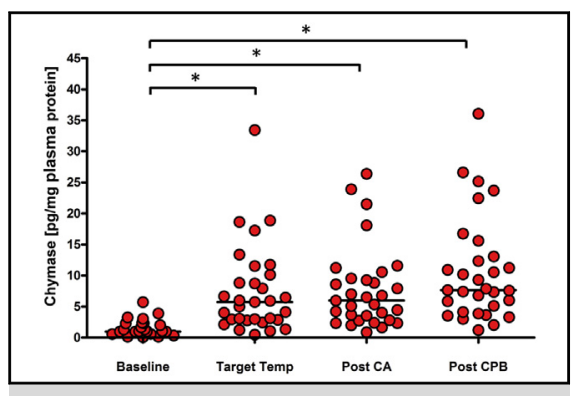

Significant release of mast cell-specific chymase during proximal aortic repair surgery.

\section{Central Message}

Mast cell activation during proximal aortic repair with hypothermic circulatory arrest is associated with hemodynamic instability.

\section{Perspective}

In patients undergoing proximal aortic repair with hypothermic circulatory arrest, we provide the first evidence that mast cell activation is an important mechanism propagating inflammatory and vasomotor disturbances. Welltolerated drugs exist to stabilize mast cells and could provide a novel therapeutic opportunity to reduce adverse systemic responses in cardiac surgery.

See Editorial Commentary page 77.

\footnotetext{
From the ${ }^{\mathrm{a} D i v i s i o n}$ of Cardiothoracic Anesthesiology, Department of Anesthesiology, ${ }^{b}$ Department of Biostatistics and Bioinformatics, ${ }^{\mathrm{c}}$ Molecular Physiology Institute, and ${ }^{\mathrm{d}}$ Division of Cardiovascular and Thoracic Surgery, Department of Surgery, Duke University Medical Center, Durham, NC.

M.D.K. and S.C. contributed equally to this article.

Supported in part by grants HL126891 (to J.A.K.) and HL109971, HL096978, and HL108280 (to J.P.M.) from the National Institutes of Health and grant 15SDG25080046 (to J.A.K.) from the American Heart Association.

Received for publication Jan 18, 2016; revisions received May 12, 2016; accepted for publication May 30, 2016; available ahead of print Sept 30, 2016.

Address for reprints: Jörn A. Karhausen, MD, Department of Anesthesiology, Duke University Medical Center, 2301 Erwin Rd, 5693 HAFS Bldg, Durham, NC 27710 (E-mail: jorn.karhausen@duke.edu).

0022-5223/\$36.00

Copyright (c) 2016 by The American Association for Thoracic Surgery

http://dx.doi.org/10.1016/j.jtcvs.2016.05.063
}

Episodes of intraoperative hypotension have been linked to adverse outcomes such as end-organ injury and mortality. In cardiac surgery, complex vasomotor disturbances lead to hypotension through generalized vasoplegia and threaten adequate organ perfusion through endothelial leakage and

Scanning this QR code will take you to the supplemental figures, tables and video for this article. 


$$
\begin{aligned}
& \text { Abbreviations and Acronyms } \\
& \begin{array}{ll}
\Delta \text { chymase } & =\text { delta baseline chymase } \\
\mathrm{CPB} & =\text { cardiopulmonary bypass } \\
\mathrm{HCA} & =\text { hypothermic circulatory arrest } \\
\mathrm{IL} & =\text { interleukin } \\
\mathrm{I} / \mathrm{R} & =\text { ischemia/reperfusion } \\
\mathrm{LT} & =\text { leukotriene } \\
\mathrm{MAP} & =\text { mean arterial pressure } \\
\mathrm{MC} & =\text { mast cell } \\
\mathrm{TNF} \alpha & =\text { tumor necrosis factor alpha }
\end{array}
\end{aligned}
$$

associated tissue edema (reviewed elsewhere ${ }^{2}$ ). In fact, up to $25 \%$ of cardiac surgery patients develop a vasoplegic syndrome, a form of distributive shock that is linked to increased length of stay and mortality. ${ }^{3,4}$ But even in less dramatic manifestations, prolonged periods spent outside a still poorly defined optimal perfusion range affect postoperative outcomes. ${ }^{5,6}$ Currently, the factors that cause such hemodynamic shifts during cardiac surgery are not well understood, impeding substantial advancement of patient care beyond supportive measures.

We have recently shown in a rat model that mast cells (MCs) play an important role in early inflammatory and tissue injury responses following deep hypothermic circulatory arrest. ${ }^{7}$ As evidenced by their pivotal role in asthma and anaphylaxis, MCs can rapidly launch local and systemic inflammatory responses through release of potent mediators from preformed stores. These effectors can dramatically change vasomotor function (eg, heparin, histamine, and prostaglandins), endothelial integrity (eg, proteases, prostaglandins, and vascular endothelial growth factor), and can activate further inflammatory components (eg, chemokines and cytokines) (reviewed elsewhere ${ }^{8}$ ). This identifies MCs as crucial regulators of vascular integrity, tone, and function and as a potent factor in the propagation of systemic inflammation.

Establishing significant MC activation in cardiac surgery constitutes a first step toward establishing a possible causative role of MCs in the development of hemodynamic disturbances and systemic inflammatory activation. Here, we present the first study that specifically addresses the activation pattern of MCs during aortic surgery by measuring intraoperative plasma chymase levels, an MC-specific protease stored in intracellular vesicles and rapidly released upon MC stimulation. Based on our experimental data ${ }^{7}$ and the pronounced inflammatory responses regularly observed, we targeted our study to patients undergoing proximal aortic repair necessitating hypothermic circulatory arrest (HCA) (see Videos 1-3 for representative procedures). Furthermore, as a first exploration into the clinical relevance, we characterized the perioperative setting in which MC responses occur and examined their association to intraoperative hypotension.

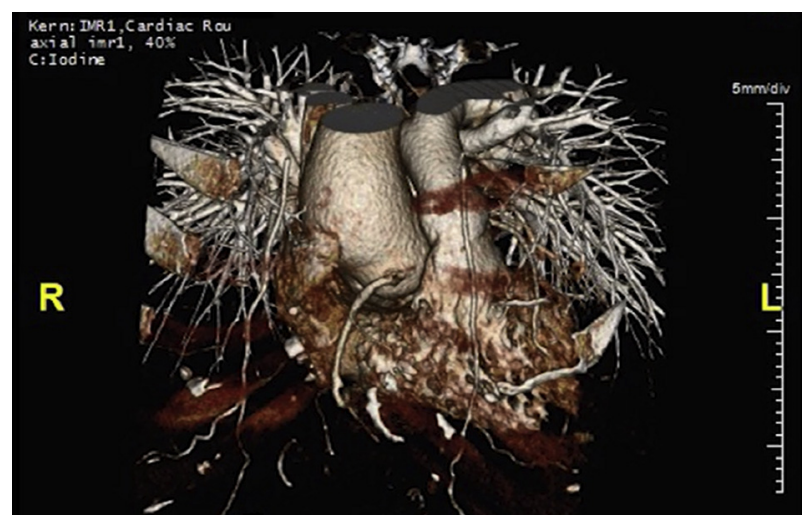

VIDEO 1. An example of proximal aortic repair surgery requiring hypothermic circulatory arrest at the Duke University Medical center. Part 1: Case presentation, cannulations including right axillary cannulation and crossclamp. Video available at: http://www.jtcvsonline.org/article/S00225223(16)31100-X/addons.

\section{METHODS}

\section{Patient Selection and Data Collection}

As part of our ongoing research effort, we conducted a pilot study to define inflammatory responses and cognitive outcomes in patients undergoing proximal aortic arch surgery and requiring HCA between June 2013 and April 2015 at the Duke University Medical Center. The Institutional Review Board for Clinical Investigations at Duke University Medical Center approved this study and informed consent was obtained preoperatively from all patients. We included all patients aged $\geq 40$ years except those with a history of symptomatic cerebrovascular disease and substantial residual deficit, alcoholism, psychiatric illness, renal failure (creatinine $>2.0 \mathrm{mg} / \mathrm{dL}$ ), or those with less than a seventh-grade education, or unable to complete neuropsychological testing or cranial magnetic resonance imaging. Patient data were extracted from the electronic health record software (Epic, Verona, Wis) and included patient demographic characteristics, procedure type, preoperative medications, pre- and

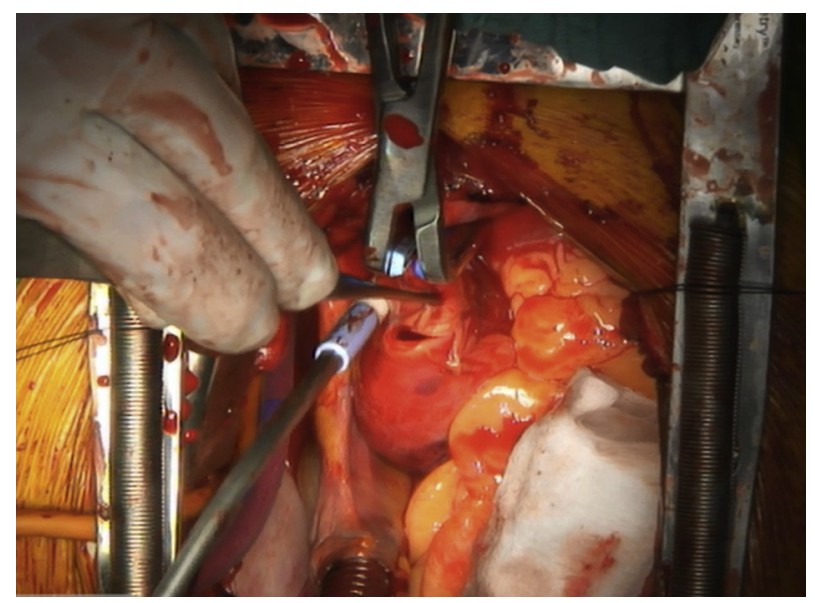

VIDEO 2. An example of proximal aortic repair surgery requiring hypothermic circulatory arrest at the Duke University Medical center. Part 2: Moderate hypothermic circulatory arrest with antegrade cerebral perfusion, transverse aortic arch reconstruction (Hemi-Arch), and preparation of the aortic root for reconstruction. Video available at: http://www.jtcvsonline.org/article/S0022-5223(16)31100-X/addons. 


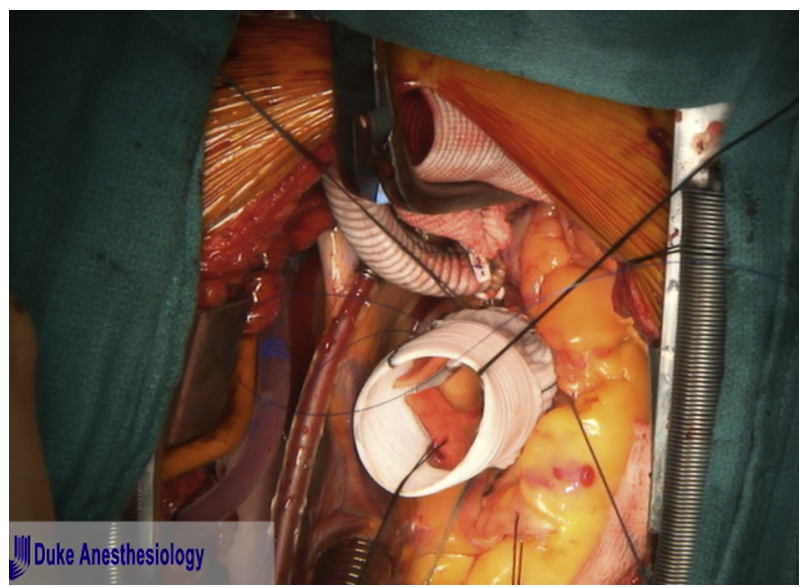

VIDEO 3. An example of proximal aortic repair surgery requiring hypothermic circulatory arrest at the Duke University Medical center. Part 3: T. David-V valve-sparing aortic root replacement with coronary reconstruction and anastomosis of aortic arch graft and aortic root graft. Video available at: http://www.jtcvsonline.org/article/S0022-5223(16)31100-X/addons.

intraoperative drug administration, laboratory values, and timing of intraoperative events. Cumulative doses of vasopressor drugs were normalized to body weight and calculated from the total intraoperative doses of norepinephrine (in micrograms), epinephrine (in micrograms), and vasopressin (in international units). Mean arterial pressures (MAPs) from the left radial arterial line were electronically charted every minute. Values $<30 \mathrm{~mm} \mathrm{Hg}$ or $>250 \mathrm{~mm} \mathrm{Hg}$ were excluded as artifactual.

\section{Anesthesia, Surgery, and Cardiopulmonary Bypass}

Anesthesia, surgical, and postoperative care were provided according to the standards of care established for proximal aortic arch surgery requiring HCA at Duke University Medical Center. General anesthesia was induced with midazolam and/or propofol, fentanyl, and rocuronium or cisatracurium before tracheal intubation. Anesthesia was maintained using isoflurane in an air-oxygen mixture with an inspiratory oxygen concentration $\geq 50 \%$ and end-tidal anesthetic gas concentrations were monitored throughout the case. As part of this institution's neuroprotection protocol, all patients received $1000 \mathrm{mg}$ methylprednisolone intravenously in the preoperative area. Surgery was performed by median sternotomy with intraoperative transesophageal echocardiographic and invasive arterial blood pressure monitoring as previously described. ${ }^{9}$ Temperature management during circulatory arrest was determined at the surgeon's discretion. Patients undergoing moderate $\mathrm{HCA}$ were cooled to $20^{\circ} \mathrm{C}$ to $26^{\circ} \mathrm{C}$ as defined by nasopharyngeal temperature, whereas for patients undergoing deep HCA, cooling was performed until electrocerebral inactivity was demonstrated by electroencephalography. Upon completion of cooling, the circulation was halted to allow opening of the aortic arch. Adjunctive antegrade $(n=30)$ or retrograde cerebral perfusion $(n=1)$ was used for cerebral protection in all cases. After completion of the hemiarch anastomosis, cardiopulmonary bypass (CPB) was reinstituted. After a 5-minute period of cold reperfusion, patients were carefully rewarmed and additionally required cardiac procedures were completed. Weaning from $\mathrm{CPB}$ was performed at a core temperature of $36^{\circ} \mathrm{C}$. Antifibrinolytic therapy using aminocaproic acid was routinely administered intraoperatively. Transfusion decisions were made according to Society of Cardiovascular Anesthesiologists/Society of Thoracic Surgeons published guidelines ${ }^{10}$ using surgical field observations, chest tube output, activated clotting time, platelet count, fibrinogen level, thrombelastogram data, and prothrombin and partial thromboplastin time tests. Antiplatelet therapy was held preoperatively except for $81 \mathrm{mg}$ aspirin and was restarted on postoperative day 1 unless active bleeding was present.

\section{Sample Collection and Analysis}

Study blood samples were drawn from the arterial line into ethylenediaminetetraacetic acid tubes following induction of anesthesia (baseline) when reaching the target temperature before HCA (target temp), 5 minutes after HCA (post-HCA), and after terminating CPB (post-CPB) (see Figure 1). Samples were immediately transferred to ice, centrifuged, and plasma was stored at $-80^{\circ} \mathrm{C}$ until analysis. The following enzyme-linked immunosorbent assays were performed: chymase (Antibody Online, Aachen, Germany), interleukin (IL)-6, IL-8, and tumor

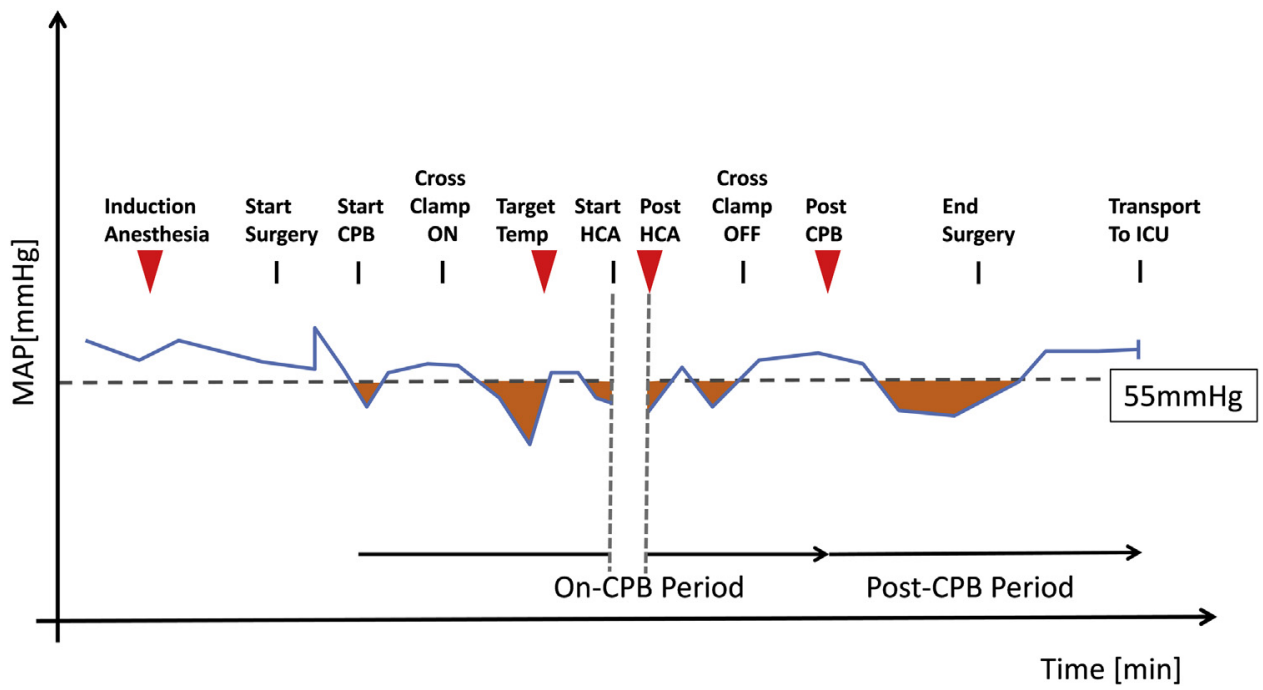

FIGURE 1. Sample draw time-points and hemodynamic quantitation strategy. Relevant time-points are graphed versus time against an idealized mean arterial pressure (MAP) tracing (blue line). A cutoff of $55 \mathrm{~mm} \mathrm{Hg}$ was chosen and the area (in minutes $\times$ millimeters mercury) underneath the cutoff was calculated (orange shaded areas). Cumulative values were then determined for an on-cardipulmonary bypass (CPB) period (excluding hypothermic circulatory arrest $[\mathrm{HCA}]$ period) and a post-CPB period. Red triangles denote blood draw. ICU, Intensive care unit. 
necrosis factor alpha (TNF $\alpha)$ (eBioscience, San Diego, Calif). Results were normalized against the protein content of the respective sample, as determined by Bradford assay (BioRad, Hercules, Calif) to account for hemodilution during CPB. In addition, leukocytes were isolated from the buffy coat following the separation of plasma. After hypotonic lysis of residual red blood cells, leukocytes were fixed and stained with allophycocyanin (APC)-coupled anti-CD45 (BD Pharmigen, San Jose, Calif) and fluorescein isothiocyanate (FITC)-coupled anti-CD11b antibody (eBioscience, San Diego, Calif) and the percentage of CD11b-positive cells in the CD45-gated population was established by fluorescence-activated cell sorting. Lactate levels were obtained as part of routine blood gas analyses and the difference between the first measurement after anesthesia induction and the last before transport to the intensive care unit was calculated.

\section{Statistical Analysis}

Continuous variables are presented as means \pm standard deviation or medians (interquartile range), and categorical variables as group frequencies and percentages. Measured values of inflammatory markers at target temperature, post-HCA, and post-CPB were compared with baseline values using Wilcoxon signed rank test. Repeated measures analysis using generalized estimating equations was performed to examine the trends over time for the serum measurements of chymase, IL-8, and CD11b but not for IL-6 and TNF $\alpha$ because of missing values at the post-HCA and post-CPB time points.

Intraoperative hypotension was defined as episodes with an MAP below $55 \mathrm{~mm} \mathrm{Hg}$. This was quantified as cumulative area (in minutes $\times$ millimeters mercury) between the actual MAP and $55 \mathrm{~mm}$ $\mathrm{Hg}$, using a modification of the approach from Levin and colleagues. ${ }^{3}$

Testing for an association between inflammatory marker measurements and hypotension was performed for 2 intraoperative time periods (Figure 1). The on-CPB period extended from initiation of $\mathrm{CPB}$ to termination of CPB, excluding the time of circulatory arrest. The post-CPB period was defined as the interval between $\mathrm{CPB}$ termination and the last valid MAP reading before transfer to the intensive care unit. The MAP area below $55 \mathrm{~mm} \mathrm{Hg}$ from these periods was examined against the delta baseline chymase ( $\Delta$ chymase) value at the target temperature measurement (for on-CPB period) and at the post-CPB measurement (for post-CPB period). Upon examination of the distribution of $\Delta$ chymase measurements, we found that they had a non-normal distribution. We attempted several different methods of data transformation, but none of these transformation techniques resulted in a normal distribution or showed a linear association with MAP area below $55 \mathrm{~mm} \mathrm{Hg}$. This precluded us from using linear analysis models and nonlinear methods such as smoothing splines did not improve model fit. Therefore, we decided to dichotomize chymase responses as outlined below. Because there is no predefined threshold for chymase, we evaluated each possible $\Delta$ chymase dichotomization cutoff for its relationship to MAP area below $55 \mathrm{~mm} \mathrm{Hg}$, using either 2 samples $t$ test or Wilcoxon rank sum test. To determine the optimal cutoff, we first defined a candidate region where consistent association signals were observed between $\Delta$ chymase values and MAP area below $55 \mathrm{~mm} \mathrm{Hg}$. Then, we chose cutoffs that yielded significant differences and a balanced grouping between high and low responders. The chosen cutoffs were close to (for the on-CPB period) or identical to (for the post-CPB period) the median. C-indices, as estimates of prediction accuracy determined by logistic regression for the chosen $\Delta$ chymase cutoff by MAP area, were 0.697 and 0.742 , respectively. These $\Delta$ chymase cutoff values were then used to dichotomize our cohort into high-responders and low-responders (measured responses above or below cutoff value for respective time period).

The same search method was applied to examine the association of IL-6, IL- $8, \mathrm{TNF} \alpha$, and CD11b with MAP area below $55 \mathrm{~mm} \mathrm{Hg}$. However, no reliable cutoff could be determined using the above approach and we therefore used the median for these biomarkers.
Univariable and multivariable logistic regression analyses were applied to evaluate the association between perioperative variables and increased chymase responder status as determined at the post-CPB blood draw. We examined preoperative risk factors, including those from the European System for Cardiac Operative Risk Evaluation score, ${ }^{11}$ the durations of $\mathrm{CPB}, \mathrm{HCA}$, and aortic crossclamp, the temperature during circulatory arrest, and the amount of blood product transfusions. Variables with $P<.05$ from the univariable analyses were tested for collinearity and entered into a multivariable logistic model. Backward stepwise selection was used for the final multivariable logistic model. Odds ratios and corresponding 95\% confidence limits are reported in Table 1. All analyses were performed using the SAS version 9.3 (SAS Institute Inc, Cary, NC).

\section{RESULTS}

A total of 31 patients (22 men, 9 women) aged $60.1 \pm 12.6$ years were recruited to this study. Patient characteristics and details of the procedures performed are outlined in Table 2.

Measurements of inflammatory responses are shown in Figure 2 and detailed in Table E1. MC-specific chymase increased significantly from a baseline median of $0.97 \mathrm{pg} / \mathrm{mg}$ (interquartile range [IQR], 0.01-1.84 $\mathrm{pg} / \mathrm{mg}$ ) plasma protein, to a median of $5.74 \mathrm{pg} / \mathrm{mg}$ (IQR, 2.92-9.48 pg/mg) plasma protein with institution of CPB and cooling. Chymase levels did not increase substantially with reperfusion after HCA (median, $6.16 \mathrm{pg} / \mathrm{mg}$ [IQR, $3.60-9.41 \mathrm{pg} / \mathrm{mg}$ ] plasma protein), but rose slightly to a median of $7.64 \mathrm{pg} / \mathrm{mg}$ (IQR, 4.63-12.71 pg/mg) plasma protein after completing CPB $(P<.0001$ vs baseline for all time points). IL-8 showed a similar response, increasing from a median of $0.27 \mathrm{pg} / \mathrm{mg}$ (IQR, $0.19-0.40 \mathrm{pg} / \mathrm{mg}$ ) plasma protein at baseline to a median of $0.46 \mathrm{pg} / \mathrm{mg}$ (IQR, 0.35-0.75 pg/mg), $0.65 \mathrm{pg} / \mathrm{mg}$ (IQR, 0.35-0.89 $\mathrm{pg} / \mathrm{mg}$ ), and $0.67 \mathrm{pg} / \mathrm{mg}$ (IQR, 0.51-1.04 pg/mg) plasma protein at target temperature, post-HCA and post-CPB, respectively $(P<.0001$ vs baseline for all time points). Similarly, we found that neutrophil activation occurred early during surgery, with the percentage of CD11bpositive and CD45-positive cells increasing from a median of $15.7 \%$ (IQR, $7.9 \%-26.6 \%$ ) at baseline to a median of $20.5 \%$ (IQR, 14.4\%-30.9\%), 27.1\% (IQR, 15.6\%-40\%), and $30.2 \%$ (IQR, $20.7 \%-50.3 \%$ ) at target temperature, post-HCA, and post-CPB, respectively $(P<.0001$ vs baseline for all time points). In contrast, TNF $\alpha$ and IL-6 rose only at the later time points of surgery; that is, TNF $\alpha$ from a median of $0.19 \mathrm{pg} / \mathrm{mg}$ (IQR, 0.11-0.28 pg/mg) plasma protein at baseline to a median of $0.39 \mathrm{pg} / \mathrm{mg}$ (IQR, $0.11-0.49 \mathrm{pg} / \mathrm{mg})$ at post-CPB $(P<.0001$ vs baseline) and IL-6 from a median of $0.08 \mathrm{pg} / \mathrm{mg}$ (IQR, $0.03-0.11 \mathrm{pg} / \mathrm{mg}$ ) plasma protein at baseline to a median of $0.28 \mathrm{pg} / \mathrm{mg}$ (IQR, 0.13-1.02 pg/mg) plasma protein post-CPB $(P<.0001$ vs baseline $)$. Repeated measure analysis of chymase, IL- 8 , and CD11b levels taken at different intraoperative time points significantly increased over time from baseline. (Figure E1). 
TABLE 1. Univariable and multivariable analysis

\begin{tabular}{|c|c|c|c|c|c|c|c|c|}
\hline \multirow[b]{2}{*}{ Variable } & \multicolumn{4}{|c|}{ Univariable analysis } & \multicolumn{4}{|c|}{ Multivariable analysis } \\
\hline & Odds ratio & 95\% CI LL & $95 \%$ CI UL & $P$ value & Odds ratio & $\mathbf{9 5} \%$ CI LL & 95\% CI UL & $P$ value \\
\hline Gender (M vs F) & 0.35 & 0.06 & 1.68 & .2009 & & & & \\
\hline Age (y) & 1.03 & 0.98 & 1.10 & .2836 & & & & \\
\hline Preoperative calcium blocker & 2.31 & 0.20 & 53.10 & .5142 & & & & \\
\hline Preoperative ACE inhibitor/ARB & 4.50 & 1.03 & 22.98 & .0544 & & & & \\
\hline Preoperative $\beta$-blocker & 0.39 & 0.09 & 1.63 & .2045 & & & & \\
\hline ASA (4 vs 3) & 0.86 & 0.20 & 3.61 & .8326 & & & & \\
\hline Chronic renal insufficiency & 1.08 & 0.12 & 10.07 & .9449 & & & & \\
\hline Previous cardiac surgery & 2.31 & 0.20 & 53.10 & .5142 & & & & \\
\hline Preoperative EF (TEE) ( $>50$ vs $31-50$ ) & 2.00 & 0.17 & 45.99 & .5887 & & & & \\
\hline PMH allergy/autoimmune Disease & 4.33 & 0.90 & 25.54 & .0788 & & & & \\
\hline Hemoglobin preoperative (g/dL) & 0.32 & 0.11 & 0.69 & .0157 & 0.32 & 0.08 & 0.78 & .0370 \\
\hline WBC count preoperative $\left(10^{9} / \mathrm{L}\right)$ & 0.75 & 0.40 & 1.33 & .3341 & & & & \\
\hline Platelet count preoperative $\left(10^{9} / \mathrm{L}\right)$ & 1.00 & 0.99 & 1.02 & .5729 & & & & \\
\hline Preinduction MAP (mm Hg) & 0.97 & 0.92 & 1.02 & .2424 & & & & \\
\hline Additional valve surgery & 8.36 & 1.61 & 65.89 & .0198 & & & & \\
\hline CPB time (min) & 1.00 & 0.99 & 1.02 & 6479 & & & & \\
\hline Crossclamp time (min) & 1.00 & 0.98 & 1.02 & .8484 & & & & \\
\hline HCA time (min) & 1.06 & 0.95 & 1.20 & .2998 & & & & \\
\hline $\mathrm{NP}$ temp at circulatory arrest $\left({ }^{\circ} \mathrm{C}\right)$ & 1.34 & 1.08 & 1.75 & .0146 & 1.36 & 1.07 & 1.89 & .0276 \\
\hline MAP area on-CPB $(\mathrm{mm} \mathrm{Hg} \times \min )$ & 1.00 & 1.00 & 1.01 & .2116 & & & & \\
\hline Postoperative EF (TEE) (>50 vs $31-50$ ) & 2.40 & 0.50 & 13.79 & .2896 & & & & \\
\hline Transfusion RBC (units) & 4.71 & 1.53 & 24.07 & .0259 & & & & \\
\hline Transfusion FFP (units) & 0.96 & 0.69 & 1.31 & .7916 & & & & \\
\hline Transfusion platelets (units) & 1.45 & 0.53 & 4.50 & .4842 & & & & \\
\hline Transfusion cryoprecipitate (units) & 0.78 & 0.300 & 1.94 & .5929 & & & & \\
\hline Hemoglobin postoperative (g/dL) & 0.97 & 0.40 & 2.30 & .9381 & & & & \\
\hline WBC count $24 \mathrm{~h}$ postoperative $(1000 / \mu \mathrm{L})$ & 1.07 & 0.90 & 1.30 & .4534 & & & & \\
\hline WBC count $48 \mathrm{~h}$ postoperative $(1000 / \mu \mathrm{L})$ & 1.08 & 0.93 & 1.29 & .3318 & & & & \\
\hline Baseline chymase (pg/mg plasma protein) & 1.66 & 1.01 & 3.16 & .0745 & & & & \\
\hline Delta-chymase target temp (pg/mg plasma protein) & 1.43 & 1.12 & 2.05 & .0193 & & & & \\
\hline Delta-IL-6 target temp (pg/mg plasma protein) & 1.60 & 0.20 & 11.41 & .5989 & & & & \\
\hline Delta-IL-6 post-CPB (pg/mg plasma protein) & 1.51 & 0.70 & 4.15 & .3202 & & & & \\
\hline Delta-IL-8 target-temp (pg/mg plasma protein) & 0.97 & 0.31 & 3.44 & .9616 & & & & \\
\hline Delta-IL-8 post-CPB (pg/mg plasma protein) & 0.96 & 0.65 & 1.41 & .8379 & & & & \\
\hline Delta-TNF $\alpha$ target temp (pg/mg plasma protein) & 1.68 & 0.00 & 3683.40 & .8898 & & & & \\
\hline Delta-TNF $\alpha$ post-CPB (pg/mg plasma protein) & 14.04 & 0.20 & 2571.36 & .2519 & & & & \\
\hline CD11b target temp (fold increase over baseline) & 1.19 & 0.28 & 5.36 & .8169 & & & & \\
\hline CD11b post-CPB (fold increase over baseline) & 0.90 & 0.52 & 1.39 & 6318 & & & & \\
\hline
\end{tabular}

Predictors of increased chymase responses. Variables were examined against increased chymase responder status as measured at the post-CPB blood draw. Hosmer-Lemeshow goodness-of-fit: $\chi^{2}, 10 ; d f, 2 ; P$ value $=.10$. Boldface denotes statistical significance, $P \leq .05 .95 \% C I L L, 95 \%$ Confidence interval lower limit; $95 \% C I U L, 95 \%$ confidence interval upper limit; $A C E$, angiotensin-converting enzyme; $A R B$, angiotensin II receptor blocker; ASA, American Society of Anesthesiologists physical status classification system; $E F$, ejection; $T E E$, transesophageal echocardiography; $P M H$, past medical history; $W B C$, white blood cell; $M A P$, mean arterial pressure; $C P B$, cardiopulmonary bypass; $H C A$, hypothermic circulatory arrest; $N P$ temp, nasopharyngeal temperature; $R B C$, red blood cell; $F F P$, fresh-frozen plasma; $D e l t a-$, delta baseline; $I L$, interleukin; $T N F \alpha$, tumor necrosis factor alpha.

We next examined whether chymase responses were associated with increased intraoperative hypotension. As shown in Figure 3, chymase high-responders displayed a significantly increased MAP area below $55 \mathrm{~mm} \mathrm{Hg}$ during $\mathrm{CPB}$, when compared with low-responders (median, $188 \mathrm{mi}-$ nutes $\times$ mm Hg [IQR, 140-392 minutes $\times$ mm Hg] vs median, 123 minutes $\times$ mm Hg [IQR, 76-212 minutes $\times$ mm $\mathrm{Hg}$ ]; $P=.0255)$. Similarly, hypotensive episodes were significantly more pronounced after terminating CPB in chymase high-responders, compared with low-responders (median, 22.2 minutes $\times \quad \mathrm{mm} \quad \mathrm{Hg} \quad[\mathrm{IQR}, \quad 1.1-$ 88.6 minutes $\times \mathrm{mm} \mathrm{Hg}$ ] vs 0.4 minutes $\times \mathrm{mm} \mathrm{Hg}$ [IQR, 0 5.1 minutes $\times \mathrm{mm} \mathrm{Hg}$ ]; $P=.0221$ ).

In addition, chymase high-responders displayed a trend toward increased cumulative use of vasopressor drugs $(P=.07)$ as well as increased intraoperative lactate production $(P=.121)$ (Figure E2).

Subsequently, we also examined the association between, IL-6, IL-8, TNF, and CD11b and intraoperative hypotension and found that there was no statistically significant 
TABLE 2. Patient demographic characteristics and intervention details

\begin{tabular}{|c|c|}
\hline Patient variable & Result \\
\hline Age (y) & $61.23 \pm 12.4$ \\
\hline Male & $22(71)$ \\
\hline Female & $9(29)$ \\
\hline ASA I & 0 \\
\hline ASA II & 0 \\
\hline ASA III & $18(58)$ \\
\hline ASA IV & $13(41)$ \\
\hline Preoperative ACE inhibitor/ARB & $13(42)$ \\
\hline Preoperative calcium blocker & $3(10)$ \\
\hline Preoperative $\beta$-blocker & $14(45)$ \\
\hline Preoperative heparin & 0 \\
\hline Preoperative hemoglobin (g/dL) & $13.96 \pm 1.53$ \\
\hline \multicolumn{2}{|l|}{ EuroSCORE variables } \\
\hline Chronic pulmonary disease & $4(13)$ \\
\hline Extracardiac arteriopathy & $31(100)$ \\
\hline Neurological dysfunction & 0 \\
\hline Serum creatinine $>200 \mathrm{mmol} / \mathrm{L}$ & $4(13)$ \\
\hline Poor mobility & $1(3)$ \\
\hline Preoperative EF $(\mathrm{TEE})>50$ & $20(65)$ \\
\hline Preoperative EF (TEE) 31-50 & $11(36)$ \\
\hline Preoperative EF $(\mathrm{TEE})<30$ & 0 \\
\hline Recent myocardial infarction & $1(3)$ \\
\hline Pulmonary hypertension & $3(10)$ \\
\hline Previous cardiac surgery & $3(10)$ \\
\hline Diabetic on insulin & 0 \\
\hline Logistic EuroSCORE (\%) & $18.9 \pm 12$ \\
\hline \multicolumn{2}{|l|}{ Surgical variables } \\
\hline Ascending aorta only & $9(29)$ \\
\hline Ascending aorta $+\mathrm{CABG}$ & $2(6)$ \\
\hline Ascending aorta + valve & $20(65)$ \\
\hline Antegrade cerebral perfusion & $30(97)$ \\
\hline Retrograde cerebral perfusion & $1(3)$ \\
\hline CPB time (min) & $169.5 \pm 45.4$ \\
\hline Crossclamp time (min) & $118.8 \pm 35.7$ \\
\hline Circulatory arrest time (min) & $13(11-16)$ \\
\hline $\mathrm{NP}$ temp at circulatory arrest $\left[\mathrm{C}^{\circ}\right]$ & $22.4 \pm 4.0$ \\
\hline Postoperative EF $($ TEE $)>50$ & $21(68)$ \\
\hline Postoperative EF (TEE) 31-50 & $10(32)$ \\
\hline Postoperative EF (TEE) < 30 & 0 \\
\hline FFP transfusion (units) & $4(0-4)$ \\
\hline $\mathrm{RBC}$ transfusion (units) & $0(0-1)$ \\
\hline Platelet transfusion (units) & $2(1.5-2)$ \\
\hline Cryoprecipitate transfusion (units) & $0(0-1)$ \\
\hline Postoperative hemoglobin (g/dL) & $10.1 \pm 0.84$ \\
\hline
\end{tabular}

Values are expressed as mean \pm standard deviation, median (interquartile range), or $\mathrm{n}(\%)$. ASA, American Society of Anesthesiologists physical status classification system; $A C E$, angiotensin-enzyme; $A R B$, angiotensin II receptor blocker; EuroSCORE, European System for Cardiac Operative Risk Evaluation score; $E F$, ejection fraction; $T E E$, transesophageal echocardiography; $C A B G$, coronary artery bypass grafting; $C P B$, cardiopulmonary bypass; $N P$ temp , nasopharyngeal temperature; $F F P$, freshfrozen plasma; $R B C$, red blood cell.

association between any of these markers and hypotension during on-CPB or post-CPB periods (Table E2).

We next aimed at better defining the conditions related to increased chymase responses. In univariable analysis, several preoperative and intraoperative variables were significantly associated with increased $\Delta$ chymase levels at the end of CPB (Table 1). In multivariable analysis, preoperative hemoglobin, and nasopharyngeal temperature at circulatory arrest emerged as independent predictors of increased chymase responses. As such, for every gram per deciliter increase of preoperative hemoglobin, the odds for an increased chymase response was 0.32 and for every degree Celsius increase at circulatory arrest result was 1.36 times the original odds.

\section{DISCUSSION}

This study of 31 patients undergoing proximal aortic repair with $\mathrm{CPB}$ and $\mathrm{HCA}$ demonstrates, for the first time, substantial intraoperative release of the MC-specific degranulation product, chymase. Importantly, MC responses, but not other inflammatory markers, such as IL-6, IL-8, TNF $\alpha$, or CD11b expression in white blood cells, were associated with significant intraoperative hypotension. Given the profound inflammatory effects of MC products in asthma and anaphylaxis, this work identified MCs as potentially crucial effectors of inflammatory and tissue-injurious signaling in cardiac surgery. Designed as a hypothesis-forming study, our data strongly encourage future research to determine whether modulation of MC activity can be used to improve outcomes in this setting. Well-established drugs that block MC degranulation exist and have been successfully used in animal models. ${ }^{\text {? }}$

Systemic inflammation following cardiac surgery is a multifactorial process, and may have profound adverse effects on injured and normal tissue. Despite compelling evidence for relevant $\mathrm{MC}$ activation in animal models of trauma, ${ }^{12}$ hemorrhagic shock, ${ }^{13}$ ischemia/reperfusion (I/R) injury, ${ }^{14}$ but also rat $\mathrm{HCA}^{7}$ and porcine extracorporeal membrane oxygenation, ${ }^{15}$ corresponding human studies have been lacking. MCs are a ubiquitously present population of potent inflammatory surveillance cells that rapidly respond to inflammatory triggers and tissue stress signals with release of preformed and de novo synthesized proinflammatory, vasoactive, and tissue-disruptive effectors (reviewed elsewhere ${ }^{8}$ ). However, previous attempts to quantify MC activation during adult or pediatric cardiac surgery have yielded incoherent results. ${ }^{16-18}$ Fayaz and colleagues $^{16}$ observed rapid histamine release upon initiation of $\mathrm{CPB}$, but dismissed MCs as the source because of concurrently decreasing MC-tryptase levels. Based on our own unpublished observations, we think that tryptase binding to heparin may interfere with detection in the setting of CPB. Instead, in our hands chymase constituted a robust marker of MC activation during cardiac surgery. These chymase measurements showed that in contrast to the rat model, ${ }^{7} \mathrm{MC}$ responses in patients were vigorous 


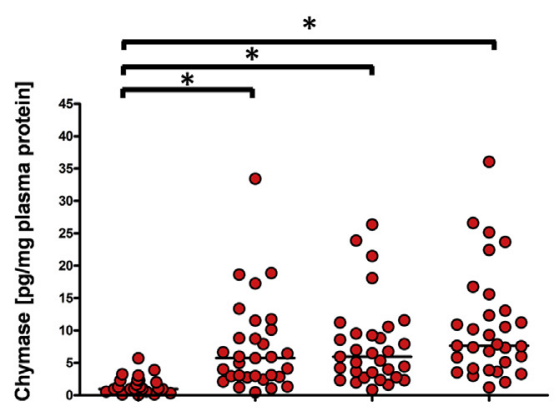

A

Baseline Target Temp Post-HCA Post-CPB

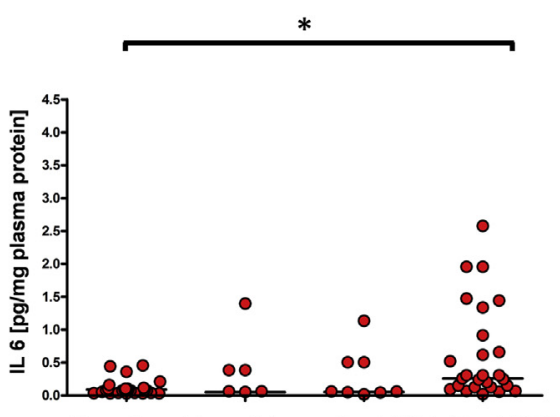

Baseline Target Temp Post-HCA Post-CPB

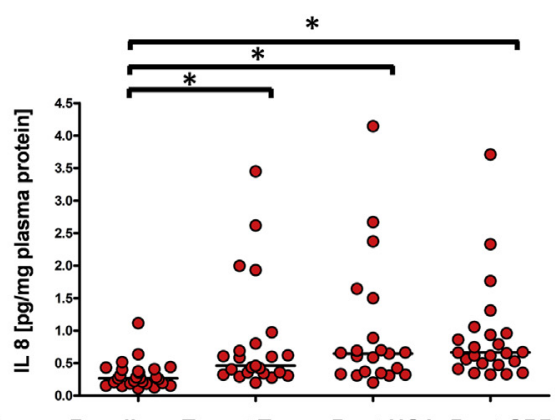

C Baseline Target Temp Post-HCA Post-CPB
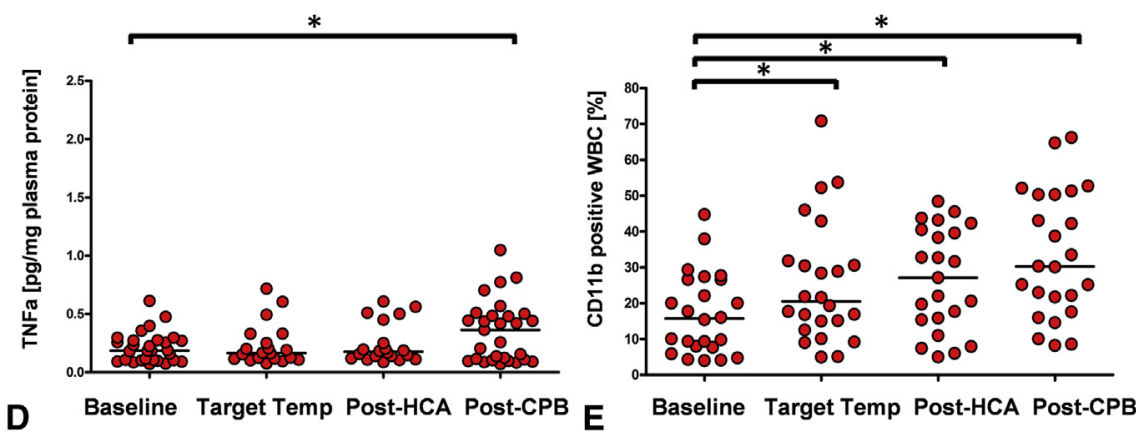

FIGURE 2. Intraoperative responses of inflammatory markers. A, Mast cell-specific chymase. B, Interleukin-6. C, Interleukin-8. D, Tumor necrosis factor alpha. E, The percentage of CD11b-positive white blood cells were determined at baseline, when reaching target temperature on cardiopulmonary bypass (Target Temp), after completion of hypothermic circulatory arrest (Post-HCA), and after completion of cardiopulmonary bypass (Post-CPB). *Increase versus baseline $P \leq .05$ by 2 -sample $t$ test.

after implementation of $\mathrm{CPB}$ and cooling, but marginal after HCA. Increased age and comorbidities may make patients (vs young, healthy rats) more sensitive to the inflammatory and circulatory challenges of extracorporeal perfusion. We are currently examining the implications of these findings by examining MC activation in coronary artery bypass grafting procedures. Furthermore, it is noteworthy that MC responses occurred in patients receiving $1000 \mathrm{mg}$ methylprednisolone as part of a neuroprotection protocol. Chymase, but also a significant portion of early cytokine release, stems from degranulation of preformed stores, ${ }^{15}$ a process that appears unaffected by steroids. ${ }^{19}$

As the first report on MC activation in a cardiac surgical setting, the present study offers important insights into a possible role for MCs in perioperative responses. Most importantly, this work demonstrated an association between amplified MC responses and intraoperative hypotension. Circulatory instability is often the first clinical
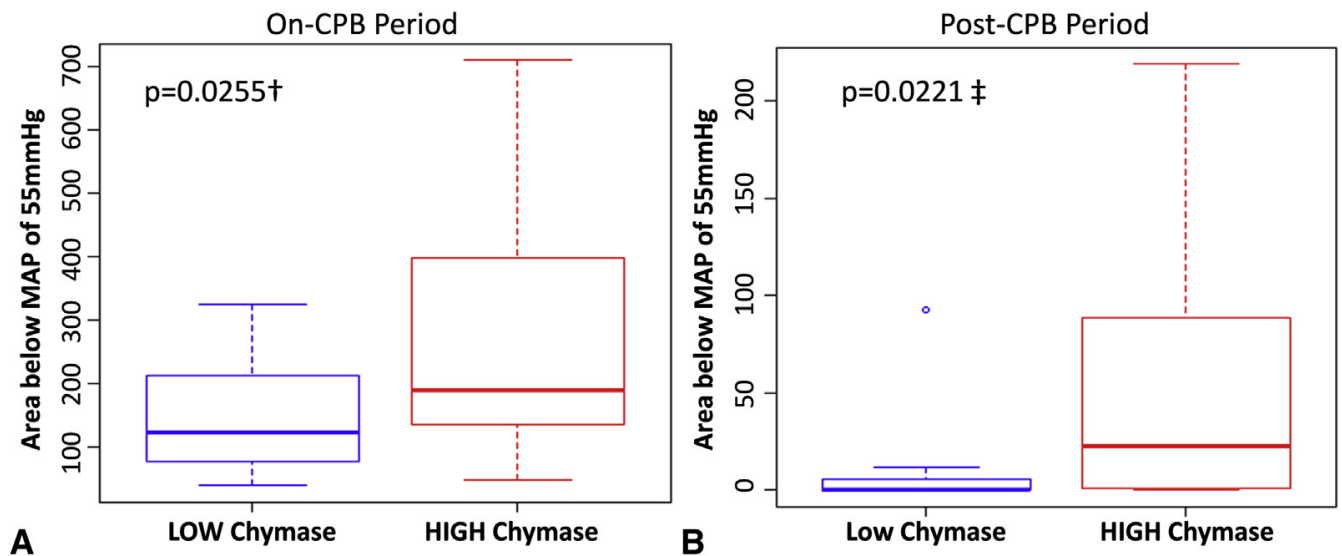

FIGURE 3. Association of plasma chymase responses and intraoperative hypotension. Delta-baseline chymase responses were dichotomized according to the cutoffs chosen for the entire cohort, using chymase levels. A, Target-temperature blood draw for the on-cardiopulmonary bypass (CPB) period. B, At the post-CPB blood draw for the post-CPB period. Hypotensive episodes were quantified by calculating the cumulative area of mean arterial pressure (MAP) below a cutoff of $55 \mathrm{~mm} \mathrm{Hg}$ (in minutes $\times$ millimeters mercury). $\dagger$ Two-sample $t$ test. $\stackrel{\dagger}{ }$ Wilcoxon rank sum test. 
manifestation of inflammatory events and presents as a predominantly distributive hypotension with inadequate responses to volume expansion. In cardiac surgery, $10 \%$ to $20 \%$ of patients develop vasoplegic syndrome, which substantially influences immediate clinical care and postoperative outcomes. ${ }^{3,4}$ Although this study was not designed to support conclusions on whether $\mathrm{MC}$ responses are a cause or effect of hypotension, available data support the notion that MC activation occurs early and promotes inflammation and vasomotor disturbances. Our previous work in a rat model of HCA has shown that pretreatment with the MC stabilizer cromolyn sodium reduced local and systemic inflammation. ${ }^{7}$ In addition, MC products have a critical effect on vascular functions. Due to their predominant perivascular distribution, MC mediators may almost immediately influence vascular structures and trigger endothelial barrier breakdown, plasma leakage, and edema (vascular endothelial growth factor, TNF $\alpha$, the eicosanoids leukotriene [LT] $\mathrm{C}_{4}, \mathrm{LTD}_{4}$, and $\mathrm{LTE}_{4}$, and the proteases tryptase and chymase) and cause vasomotor disturbances (histamine and chymase). ${ }^{8}$

$\mathrm{CPB}$ and HCA constitute an extremely complex context and multiple events such as I/R, ${ }^{14}$ complement activation, ${ }^{20}$ and cytokine release ${ }^{21}$ may stimulate MCs. Here, our uniand multivariable analyses provide additional evidence of the clinical setting in which MC activation occurs.

As such, increased chymase responses were associated with higher target temperatures at circulatory arrest. A number of recent works ${ }^{22,23}$ have highlighted advantages of performing circulatory arrest procedures at higher temperatures. However, the consequences on $\mathrm{I} / \mathrm{R}$ injury and systemic inflammatory responses are not yet fully defined. ${ }^{9,24}$ In fact, conflicting results have been reported on the temperature-dependency of cytokine release in cardiac cases. ${ }^{25,26}$ Consistent with a previous report, ${ }^{13}$ our data suggest that MC degranulation is blunted at low temperatures, but, as with Rasmussen and colleagues, ${ }^{26}$ other inflammatory markers were not affected (data not included). Our previous work in a rat model of HCA revealed substantial intestinal I/R injury. ${ }^{7}$ Therefore, although ante- or retrograde cerebral perfusion is thought to confer some degree of brain protection, a concern remains as to $\mathrm{I} / \mathrm{R}$ injury of abdominal organs. Increased MC activation at higher HCA temperatures may reflect suboptimal ischemic protection at these sites, but further studies are needed to define resultant injury patterns better.

We also observed that low preoperative hemoglobin levels were independent predictors of above-median MC responses. Preoperative anemia reduces oxygen delivery and thus increases the risk of end-organ injury during cardiac surgery. ${ }^{27}$ It is possible that both anemia and HCA temperature influence MC activation and related perioperative inflammatory responses through their role in I/R injury. On the other hand, red blood cell transfusions were associated with increased chymase responses in univariable, but not in multivariable, analysis. There is ample evidence that red blood cell transfusion may directly contribute to adverse clinical outcomes in cardiac surgery. ${ }^{28,29}$ Although the mechanisms by which transfusions elicit injurious responses remain unknown, there appears to be a distinct inflammatory component. ${ }^{30}$ Apart from anaphylactic transfusion reactions, $\mathrm{MC}$ activation has been reported due to immunoglobulin $\mathrm{E}$ oligomers in donor plasma ${ }^{31}$; however, future studies will have to determine if MCs are also involved in mediating a more general inflammatory response to transfusion.

\section{Study Limitations}

Our small-scale study was designed as an exploratory study to identify the presence of MC activation in our cohort and to characterize the clinical setting in which MC activation occurs. To overcome some of the challenges of our limited cohort while still attempting to explore the clinical relevance of $\mathrm{MC}$ activation, we analyzed intraoperative hypotension because a dense dataset of MAP measurements was available through electronic charting. It must be noted that we do not routinely use pulmonary artery catheters in these cases. Although independent evaluation by a boardcertified echocardiographer pre- and postprocedure did not reveal a significant deterioration of cardiac function, we thus could not calculate vascular resistance as a measure of vasoplegia. ${ }^{4}$ Instead, we defined hypotension as an MAP below $55 \mathrm{~mm} \mathrm{Hg}$, which according to various reports from cardiac and noncardiac surgery settings showed a strong association between the time spent below this threshold and perioperative adverse outcomes. ${ }^{1,32,33}$

In addition, we found that the distribution of biomarker measurements did not allow analysis using linear models and we therefore resorted to dichotomizing chymase levels into high and low responders. Although we strongly believe that the robust association between hypotension and elevated chymase levels supports the clinical relevance of perioperative $\mathrm{MC}$ activation as a concept, this approach may limit the generalizability of our study findings.

Lastly, data on clinical risk factors, medication use, and laboratory values were retrospectively retrieved from electronic medical records. Thus, the effects of certain risk factors and medications may have been biased. In addition, specimen volume was too limited in some patients to measure all of the inflammatory markers.

\section{CONCLUSIONS}

We demonstrated, for the first time, significant MC activation during proximal aortic repair surgery requiring circulatory arrest. Multivariable logistic regression analysis indicated that increased circulatory arrest temperatures and low preoperative hemoglobin contribute to such MC 
activation. Importantly, MC activation was significantly associated with relevant intraoperative hypotension.

\section{Conflicts of Interest Statement}

Authors have nothing to disclose with regard to commercial support.

The authors thank Laura Mitrescu, BSc, for providing technical support and Betsy W. Hale, BSc, and Austin Traylor, BSc (Department of Anesthesiology, Duke University Medical Center, Durham, NC), for providing help with data retrieval. The authors also thank Kathy Gage, BS (Department of Anesthesiology, Duke University Medical Center), for providing editorial help.

\section{References}

1. Walsh M, Ruela M, Khan TA, Voisinea P, Bianchia C, Sellkea FW. Relationship between intraoperative mean arterial pressure and clinical outcomes after noncardiac surgery: toward an empirical definition of hypotension. Anesthesiology. 2013;119:507-15.

2. Ruel M, et al. Vasomotor dysfunction after cardiac surgery. Eur J Cardiothorac Surg. 2004;26:1002-14

3. Levin MA, et al. Early on-cardiopulmonary bypass hypotension and other factors associated with vasoplegic syndrome. Circulation. 2009;120:1664-71.

4. Sun $X$, et al. Is vasoplegic syndrome more prevalent with open-heart procedures compared with isolated on-pump CABG surgery? Cardiovasc Revasc Med. 2011;12:203-9.

5. Ono M, et al. Duration and magnitude of blood pressure below cerebral autoregulation threshold during cardiopulmonary bypass is associated with major morbidity and operative mortality. J Thorac Cardiovasc Surg. 2014;147: 483-9.

6. Aronson S, et al. Intraoperative systolic blood pressure variability predicts 30-day mortality in aortocoronary bypass surgery patients. Anesthesiology. 2010;113:305-12.

7. Karhausen J, et al. Intestinal mast cells mediate gut injury and systemic inflammation in a rat model of deep hypothermic circulatory arrest. Crit Care Med. 2013;41:e200-10.

8. Kunder CA, St John AL, Abraham SN. Mast cell modulation of the vascular and lymphatic endothelium. Blood. 2011;118:5383-93.

9. Lima B, et al. Results of proximal arch replacement using deep hypothermia for circulatory arrest: is moderate hypothermia really justifiable? Am Surg. 2011;77: 1438-44.

10. Ferraris VA, et al; Society of Thoracic Surgeons Blood Conservation Guideline Task. 2011 update to the Society of Thoracic Surgeons and the Society of Cardiovascular Anesthesiologists blood conservation clinical practice guidelines. Ann Thorac Surg. 2011;91:944-82.

11. Nashef SA, et al. European system for cardiac operative risk evaluation (EuroSCORE). Eur J Cardiothorac Surg. 1999;16:9-13.

12. Cai C, et al. Mast cells play a critical role in the systemic inflammatory response and end-organ injury resulting from trauma. J Am Coll Surg. 2011;213:604-15.

13. Coyan GN, et al. Induced hypothermia during resuscitation from hemorrhagic shock attenuates microvascular inflammation in the rat mesenteric microcirculation. Shock. 2014;42:518-24.
14. Yang MQ, et al. The role of mast cells in ischemia and reperfusion injury Inflamm Res. 2014;63:899-905.

15. McIlwain RB, et al. Plasma concentrations of inflammatory cytokines rise rapidly during ECMO-related SIRS due to the release of preformed stores in the intestine. Lab Invest. 2010;90:128-39.

16. Fayaz KM, et al. Histamine release during adult cardiopulmonary bypass. Anaesthesia. 2005;60:1179-84.

17. Withington DE, Elliot E, Man WK. Histamine release during paediatric cardiopulmonary bypass. Agents Actions. 1991;33:200-2.

18. Valen $\mathrm{G}$, et al. Open heart surgery increases the levels of histamine in arterial and coronary sinus blood. Agents Actions. 1994;41:11-6.

19. Cohan VL, et al. Dexamethasone does not inhibit the release of mediators from human mast cells residing in airway, intestine, or skin. Am Rev Respir Dis. 1989; 140:951-4

20. Ali H. Regulation of human mast cell and basophil function by anaphylatoxins C3a and C5a. Immunol Lett. 2010;128:36-45.

21. Kaplan AP, et al. Histamine releasing factors and cytokine-dependent activation of basophils and mast cells. Adv Immunol. 1991;50:237-60.

22. Algarni KD, et al. Profound hypothermia compared with moderate hypothermia in repair of acute type A aortic dissection. J Thorac Cardiovasc Surg. 2014;148: 2888-94.

23. Tsai JY, et al. Moderate hypothermia during aortic arch surgery is associated with reduced risk of early mortality. J Thorac Cardiovasc Surg. 2013;146: 662-7.

24. Luehr M, et al. Modern temperature management in aortic arch surgery: the dilemma of moderate hypothermia. Eur J Cardiothorac Surg. 2014;45: 27-39

25. Menasche $\mathrm{P}$, et al. A potential mechanism of vasodilation after warm heart surgery. The temperature-dependent release of cytokines. J Thorac Cardiovasc Surg. 1994; 107:293-9.

26. Rasmussen BS, et al. The release of systemic inflammatory mediators is independent of cardiopulmonary bypass temperature. J Cardiothorac Vasc Anesth. 2007;21:191-6.

27. Magruder JT, et al. Nadir oxygen delivery on bypass and hypotension increase acute kidney injury risk after cardiac operations. Ann Thorac Surg. 2015;100: 1697-703.

28. Karkouti K. Transfusion and risk of acute kidney injury in cardiac surgery. $\mathrm{Br} \mathrm{J}$ Anaesth. 2012;109(Suppl 1):i29-38.

29. Shaw RE, et al. Blood transfusion in cardiac surgery does increase the risk of 5-year mortality: results from a contemporary series of 1714 propensitymatched patients. Transfusion. 2014;54:1106-13.

30. Ferraris VA, EBallert EQ, Mahan A. The relationship between intraoperative blood transfusion and postoperative systemic inflammatory response syndrome. Am J Surg. 2013;205:457-65.

31. Abe $\mathrm{T}$, et al. Immunoglobulin $\mathrm{E}$ oligomers identified in blood components activate mast cells: relevance to anaphylactic transfusion reaction. Transfusion. 2011;51:2327-36

32. Kertai MD, et al. Bispectral Index Monitoring, Duration of Bispectral Index Below 45, Patient Risk Factors, and Intermediate-term Mortality after Noncardiac Surgery in the B-Unaware Trial. Anesthesiology. 2011;114:545-56.

33. Monk TG, et al. Anesthetic management and one-year mortality after noncardiac surgery. Anesthes Analg. 2005;100:4-10.

Key Words: cardiac surgical procedures, mast cell, blood pressure, inflammation mediators 

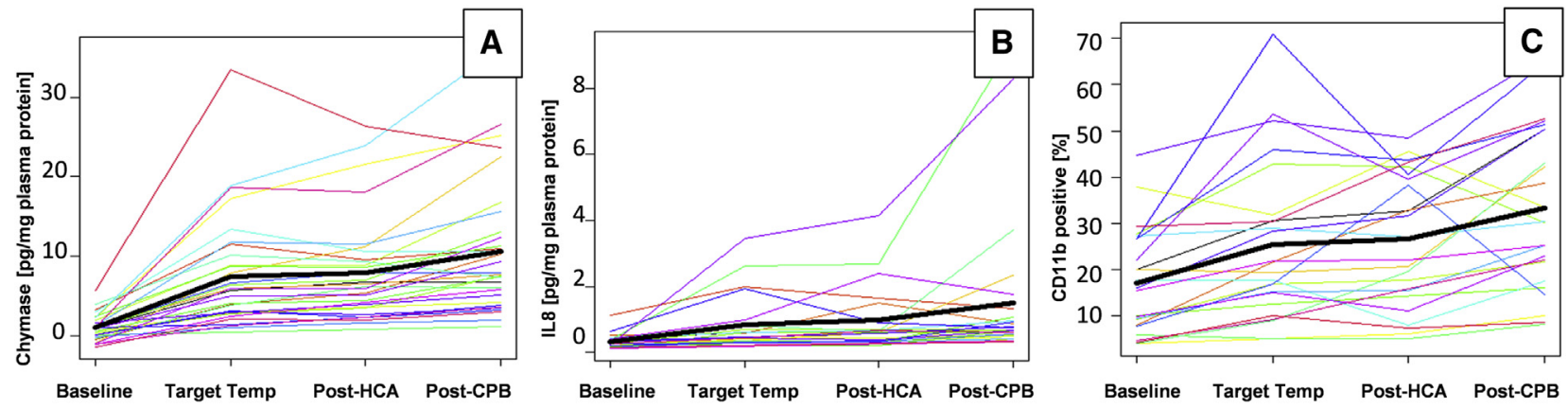

\begin{tabular}{cc|cccc}
\hline Outcome & Variable & Estimate & Std.err & Wald & $\operatorname{Pr}(>|\mathbf{W}|)$ \\
\hline Chymase & TIme & 25.37 & 5.62 & 20.4 & $\mathbf{0 . 0 0 0 0 0 6 2}$ \\
& Time^2 & -3.81 & 1.09 & 12.2 & $\mathbf{0 . 0 0 0 4 9}$ \\
\hline IL8 & Time & 2.5134 & 1.2124 & 4.3 & $\mathbf{0 . 0 3 8}$ \\
& Time^2 $^{\wedge}$ & -1.1376 & 0.5839 & 3.8 & 0.051 \\
& Time^3 & 0.1703 & 0.0878 & 3.76 & 0.052 \\
\hline CD11b & Time & 68.43 & 31.19 & 4.81 & $\mathbf{0 . 0 2 8}$ \\
& Time^2 & -28.8 & 14.42 & 3.99 & $\mathbf{0 . 0 4 6}$ \\
& Time^3 & 3.92 & 2.01 & 3.79 & 0.051 \\
\hline
\end{tabular}

FIGURE E1. Repeated measures analysis to examine the trends over time for measurements of A, Chymase, B, Interleukin-8 (IL8), and C, CD11b. The decision to transform the time scale was based on the curve of mean measurement over time as indicated by the black line in each panel. Estimate denotes the coefficient of time and denotes the slope of the median. $H C A$, Hypothermic circulatory arrest; $C P B$, cardiopulmonary bypass; Wald, Wald-type rank test; $\operatorname{Pr}(>|W|), P$ value.
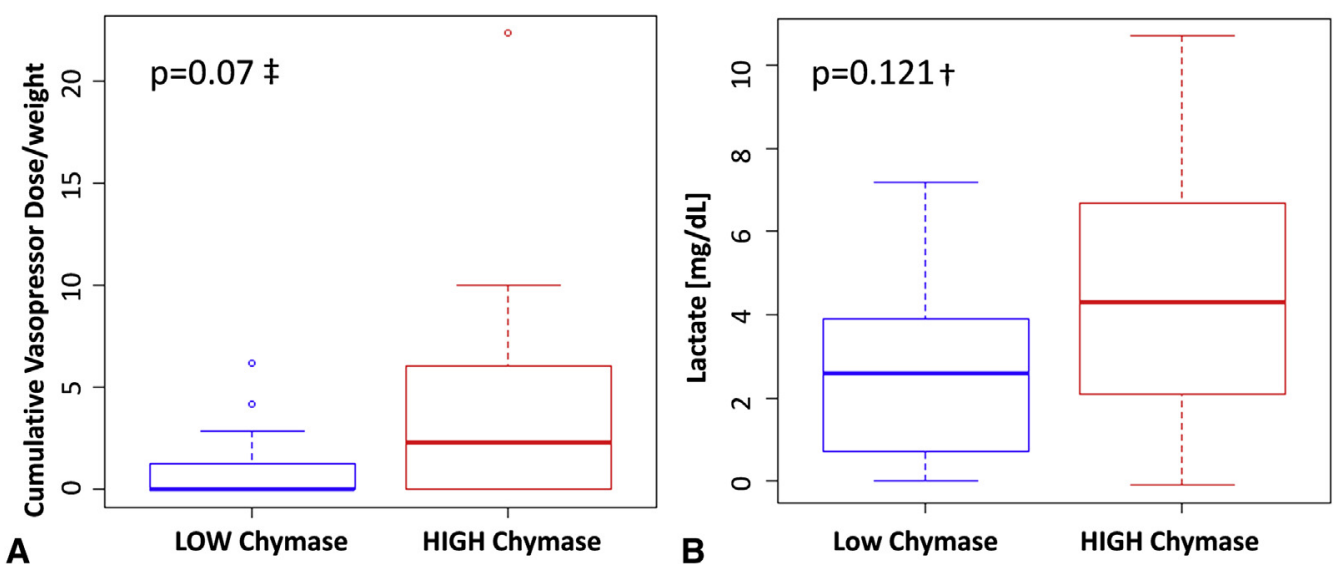

FIGURE E2. Indicators of relevant hypotension are increased in above-median chymase responders. A, Cumulative dose of vasopressors was calculated by adding total intraoperative doses of epinephrine (in micrograms), vasopressin (in international units), and norepinephrine (in micrograms) and adjusted for each patient's body weight. B, Lactate levels are represented as difference between last and first intraoperative lactate level (milligrams per deciliter). ${ }^{\dagger}$ Two-sample $t$ test. ${ }^{\ddagger}$ Wilcoxon rank sum test. 
TABLE E1. Intraoperative measurements of inflammatory markers. Measurements were determined at baseline, when reaching target temperature on cardiopulmonary bypass (CPB) (target temp), after completion of hypothermic circulatory arrest (post-HCA), and after completion of cardiopulmonary bypass (post-CPB) and are expressed for chymase, interleukin-6 (IL-6), interleukin-8 (IL-8) and tumor necrosis factor alpha (TNF $\alpha$ ) in pictograms per milligram plasma protein and for CD11b in \% CD11b positive white blood cells. Missing measurements of inflammatory markers in some cases were due to sample volume limitations. Estimates are calculated from the mean of the paired difference of a measurement and the respective baseline

\begin{tabular}{|c|c|c|c|c|c|c|c|c|}
\hline \multirow[b]{2}{*}{ Variable } & \multirow[b]{2}{*}{ Time Point } & \multirow[b]{2}{*}{$\mathbf{n}$} & \multirow[b]{2}{*}{ Median } & \multirow[b]{2}{*}{ Interquartile range } & \multicolumn{4}{|c|}{ Compared with baseline } \\
\hline & & & & & Estimate & $\mathbf{9 5} \%$ CI LL & $95 \%$ CI UL & $\begin{array}{c}\text { Wilcoxon signed } \\
\text { rank test } \\
\end{array}$ \\
\hline \multirow[t]{4}{*}{ Chymase } & Baseline & 31 & 0.97 & 0.01 to 1.84 & & & & \\
\hline & Target temp & 31 & 5.74 & 2.92 to 9.48 & 6.48 & 4.31 & 8.64 & $<.0001$ \\
\hline & Post-HCA & 31 & 6.15 & 3.60 to 9.41 & 6.89 & 4.84 & 8.93 & $<.0001$ \\
\hline & Post-CPB & 31 & 7.64 & 0.63 to 12.71 & 9.66 & 6.79 & 12.53 & $<.0001$ \\
\hline \multirow[t]{4}{*}{ IL-6 } & Baseline & 28 & 0.08 & 0.03 to 0.11 & & & & \\
\hline & Target temp & 18 & -0.08 & -0.10 to 0.04 & 0.10 & -0.18 & 0.39 & .2287 \\
\hline & Post-HCA & 18 & -0.06 & -0.10 to 0.05 & 0.07 & -0.14 & 0.28 & .3692 \\
\hline & Post-CPB & 28 & 0.28 & 0.13 to 1.02 & 0.60 & 0.20 & 1.01 & $<.0001$ \\
\hline \multirow[t]{4}{*}{ IL-8 } & Baseline & 26 & 0.27 & 0.19 to 0.40 & & & & \\
\hline & Target temp & 23 & 0.46 & 0.35 to 0.75 & 0.49 & 0.15 & 0.83 & $<.0001$ \\
\hline & Post-HCA & 21 & 0.65 & 0.35 to 0.89 & 0.62 & 0.18 & 1.06 & $<.0001$ \\
\hline & Post-CPB & 26 & 0.67 & 0.51 to 1.04 & 1.19 & 0.27 & 2.10 & $<.0001$ \\
\hline \multirow[t]{4}{*}{$\mathrm{TNF} \alpha$} & Baseline & 30 & 0.19 & 0.11 to 0.28 & & & & \\
\hline & Target temp & 20 & 0.17 & 0.12 to 0.27 & 0.05 & -0.01 & 0.11 & .0245 \\
\hline & Post-HCA & 20 & 0.18 & 0.13 to 0.30 & 0.07 & 0.01 & 0.13 & .0002 \\
\hline & Post-CPB & 30 & 0.39 & 0.11 to 0.50 & 0.15 & 0.08 & 0.22 & $<.0001$ \\
\hline \multirow[t]{4}{*}{ CD11b } & Baseline & 24 & 15.7 & 7.9 to 26.6 & & & & \\
\hline & Target temp & 24 & 20.5 & 14.4 to 30.9 & 8.42 & 3.82 & 13 & $<.0001$ \\
\hline & Post-HCA & 23 & 27.1 & 15.62 to 40.0 & 9.38 & 5.42 & 13.3 & $<.0001$ \\
\hline & Post-CPB & 24 & 30.2 & 20.7 to 50.3 & 16.21 & 10.73 & 21.7 & $<.0001$ \\
\hline
\end{tabular}

Boldface denotes statistical significance, $P \leq .05 .95 \%$ CI LL, $95 \%$ Confidence interval lower level; $95 \%$ CI UL, $95 \%$ confidence interval upper level; $H C A$, hypothermic circulatory arrest; $C P B$, cardiopulmonary bypass; $I L$, interleukin; $T N F \alpha$, tumor necrosis factor alpha.

TABLE E2. Association of inflammatory markers with intraoperative patient hemodynamic parameters for the on-cardiopulmonary bypass (CPB) and post-CPB period. Delta-baseline responses were dichotomized according to the median for the whole cohort using the respective measurement at the target-temperature blood-draw for the on-CPB period and at the post-CPB blood draw for the post-CPB period. Hemodynamic parameters were quantified by calculation of the area above the mean arterial pressure curve and below a cutoff of $55 \mathrm{~mm} \mathrm{Hg}$

\begin{tabular}{|c|c|c|c|c|c|c|c|c|}
\hline \multirow[b]{2}{*}{ Marker } & \multirow[b]{2}{*}{$\begin{array}{c}\text { Intraoperative } \\
\text { period }\end{array}$} & \multicolumn{3}{|c|}{ Below or equal to median } & \multicolumn{3}{|c|}{ Above median } & \multirow[b]{2}{*}{$P$ value } \\
\hline & & $\mathbf{N}$ & Median & $\begin{array}{c}\text { Interquartile } \\
\text { range }\end{array}$ & $\mathbf{N}$ & Median & $\begin{array}{c}\text { Interquartile } \\
\text { range }\end{array}$ & \\
\hline \multirow[t]{2}{*}{ Chymase } & On-CPB & 16 & 107.1 & $70.58-193.3$ & 15 & 193.4 & $165.7-411.8$ & $.0067 \dagger$ \\
\hline & Post-CPB & 16 & 0.3631 & $0-5.07$ & 15 & 22.24 & $1.141-88.63$ & $.0221 \dagger$ \\
\hline \multirow[t]{2}{*}{ Interleukin-6 } & On-CPB & 8 & 184.5 & 105.9-291.5 & 8 & 249.6 & 103.4-364.6 & $.6689 \dagger$ \\
\hline & Post-CPB & 13 & 0.07 & $0-7.24$ & 13 & 2.29 & $1.131-22.24$ & $.1905 \ddagger$ \\
\hline \multirow[t]{2}{*}{ Interleukin-8 } & On-CPB & 11 & 174.4 & $102-268$ & 11 & 188.7 & $129.4-244.5$ & $.7969 \ddagger$ \\
\hline & Post-CPB & 13 & 1.56 & $0-22.24$ & 12 & 4.01 & $0.8483-17.75$ & $.9559 \ddagger$ \\
\hline \multirow[t]{2}{*}{ Tumor necrosis factor alpha } & On-CPB & 10 & 218.4 & 179.6-361.6 & 10 & 135.1 & $61-331$ & $.4490 \ddagger$ \\
\hline & Post-CPB & 15 & 1.6 & $0.04-9.6$ & 15 & 7.2 & $0-71.8$ & $.6127 \ddagger$ \\
\hline \multirow[t]{2}{*}{$\mathrm{CD} 11 \mathrm{~b}$} & On-CPB & 12 & 168.7 & $121.5-187.5$ & 12 & 145.3 & $53.06-249.7$ & $.9323 \ddagger$ \\
\hline & Post-CPB & 12 & 3.27 & $0-57.37$ & 12 & 3.43 & $0-11.9$ & $.7022 \ddagger$ \\
\hline
\end{tabular}

Boldface denotes statistical significance, $P \leq .05$. †Two-sample $t$ test. $\ddagger$ Wilcoxon rank sum test. 